\title{
La corrupción como descomposición de las relaciones constitutivas del ser humano. Una reflexión teológica
}

\author{
ROMÁN ÁNGEL PARDO MANRIQUE* \\ Universidad Pontificia de Salamanca (España) \\ rapardoma@upsa.es
}

\section{Resumen}

El papa Francisco ha destacado en su magisterio la gravedad de la corrupción como una categoría moral que va más allá del propio concepto de pecado personal. Si los pecadores son perdonados, los hombres corruptos han cerrado su corazón a dicho perdón. Sus enseñanzas nos recuerdan al pecado contra el Espíritu Santo y al concepto de "pecado social". Sus palabras son de gran actualidad en una sociedad donde la corrupción se extiende como una plaga en instituciones y personas que debían dar ejemplo de honradez y responsabilidad. En este trabajo. nos acercamos al concepto de corrupción desde la perspectiva teológica, aportando luz para prevenir la corrupción y sus efectos desbastadores para la consecución del bien común y la confianza ciudadana que se tiene que dar en la vida social.

Palabras clave: Corrupción, pecado social, estructuras de pecado, globalización, salvación.

\section{The corruption as decomposition of the relationships constituting the buman being. A theological reflection}

\begin{abstract}
Pope Francis has highlighted in his teaching the seriousness of corruption as a moral category that goes beyond the concept of personal sin. If the sinners are forgiven, the corrupt men have closed his heart to such forgiveness. His teachings remind us of sin against the Holy Spirit and the concept of "social sin". His words are very interesting in today society where corruption spreads like a plague in institutions and people who should set an example of honesty and responsibility. In this paper, we approach the concept of corruption from a theological perspective, providing light to prevent corruption and its devastating effects for the achievement of the common good and the public trust that must be given in social life.
\end{abstract}

Key words: Corruption, social sin, structures of sin, globalization, salvation.

\footnotetext{
* Doctor en Teología, Universidad Pontificia de Salamanca. Profesor de Teología Moral Social en la Facultad de Teología de la Universidad Pontificia de Salamanca y Profesor invitado del Instituto San Jerónimo de la Facultad del Norte de España en su sede de Burgos. Entre sus publicaciones se encuentran: Dos filósofos conversos amigos de la virtud. Apuntes biográficos y pensamiento de Elizabeth Anscombe y Alasdair MacIntyre (2011), En Espiritu y en verdad. La Iglesia como Pueblo de Dios y la vida de los cristianos: los sacramentos y la moral (2017), así como varios artículos y colaboraciones en los campos de la Teología moral y la Bioética.
} 
El lenguaje ordinario siempre resulta esclarecedor cuando queremos acercarnos a términos complejos. En general, el uso del lenguaje que la gente corriente realiza corresponde a lo más genuino de la realidad que se quiere expresar, aunque en una sociedad globalizada - tan mediatizada por la propaganda, lo políticamente correcto y los intereses particulares influenciados por los grandes lobbies políticos, económicos y sociales- la lengua común también necesita parámetros correctivos que nos permitan llegar al significado normal de lo que se ha querido trasmitir, no sólo en el presente sino también a lo largo de la historia de los conceptos que usados en el pasado garantizan un futuro expresable con sentido.

Con todo, es verdad que siempre jugaremos con normas polisémicas y con el uso de la analogía, es decir, con la ambigüedad de comunicación de la realidad y con las profundas cuestiones epistemológicas que han llenado páginas de los más insignes pensadores de todos los tiempos. Sin embargo, los autores clásicos de la antigua Grecia eran conscientes de que para el hombre corriente las cuestiones más apremiantes eran las que correspondían con la vida práctica. Para Aristóteles, antes que todo era la política y después la ética, las cuestiones metafísicas venían después. Por eso, las posturas filosóficas de corte realista han descubierto que la descripción de tipo narrativo es esclarecedora para acercarse a la veracidad de los hechos en su dinamicidad histórica y relacional. En ese sentido, podemos comprobar que el ser humano necesita de la tribu o comunidad puede desarrollar el lenguaje y el pensamiento. Esa es la razón por la que los griegos clásicos entendían que lo primero de todo era reconocerse como ciudadano perteneciente a una polis, donde gracias a la socialización es posible madurar como un ser humano que realiza su propia naturaleza perfectiva.

Siguiendo esta línea argumentativa, descubrimos que hay conceptos y categorías que para comprenderlos en su sentido más originario debemos recurrir a un estudio al que podemos denominar "arqueológico" - lo que corresponde más técnicamente con la descripción de "etimológico"- ya que el paso del tiempo los ha llenado de adhesiones, manipulaciones y dobles sentidos. Suelen ser conceptos esenciales, pero donde todos los pensadores y culturas han querido dejar sus apreciaciones, muchas veces a costa de perder la frescura inicial semántica.

Por otra parte, hay cuestiones que nos remiten al sentido y a la finalidad más profunda de la naturaleza de los seres humanos y es aquí donde entra en juego la posibilidad de que el ser humano se trascienda y piense teológicamente; esto último, implica que el ser humano active la capacidad que posee de pensar la realidad desde Dios, lo que le permitirá escrutar 
todo lo existente desde una perspectiva del "exceso", como bien señaló en sus obras el teólogo Gesché (2004). Precisamente, esto es lo que queremos intentar en este trabajo teológico en torno a un concepto que ocupa mucho tiempo de nuestras conversaciones diarias y que no es otro que el de la corrupción, aquello que se puede definir, no sin cierta ironía, como "una cosa terrible que hacen muchos, pero siempre otros" (Santos, 2018: 70).

\section{EL USO COMÚN DEL TÉRMINO CORRUPCIÓN: ETIMOLOGÍA, SIGNIFI- CANTE Y SIGNIFICADO}

Es conveniente recurrir, como primera instancia de estudio, a la etimología de la palabra corrupción. Su origen es latino y corresponde a la palabra corruptio, la cual está compuesta del prefijo con- que muta en cor-por asimilación a la primera letra de la raíz rumpere a la que también se le añade el sufijo -tio que indica la acción y efecto del significado de la raíz. El prefijo con- añade el contenido de junto, cerca de, globalmente, al significado de rumpere: quebrar, partir, hacer pedazos, hacer estallar ${ }^{1}$. Con lo cual, podemos afirmar que etimológicamente con corrupción describimos un proceso en cuya dinámica lo que se encuentra unido y junto se separa, se quiebra, se disgrega, se descompone. Si la noción de corrupción la aplicamos al ámbito de la biología y de la química su campo significativo se orienta hacia conceptos como descomposición, putrefacción, disolución, aumento de la entropía o ruptura del sistema. Por su parte, si queremos referirnos a un sentido ético, la corrupción implica la connotación de mentir, sobornar, viciar o pervertir a alguien ya que su supuesta e inquebrantable honradez salta por los aires. Además, si unimos la etimología con la experiencia podemos - tomándonos cierta licencia—indicar que la corrupción puede conllevar el sentido de destrozar, romper, destruir junto con otros, en complicidad, de tal modo que en el campo económico y social, la corrupción nos evocará realidades como tramas comerciales o financieras de tipo mafioso, tráfico de influencias, informaciones privilegiadas o enriquecimiento ilícito entre otras plagas disgregadoras. Pero también la corrupción encuentra un ámbito propicio para su propagación en el contexto del

\footnotetext{
1 Aunque con una licencia abusiva, algunas veces se relaciona el prefijo modificado cor-con el sustantivo latino cor, cordis cuyo significado es el de corazón, por lo que corrupción haría referencia a un corazón roto. Dejando a un lado el error etimológico, dicha interpretación resulta interesante para describir al corrupto, como así parece que quiere hacer el papa Francisco en los siguientes términos: "La corrupción nace de un corazón corrupto y es la peor plaga social, porque genera gravísimos problemas y crímenes, que implican a todos. La palabra 'corrupto' recuerda el corazón roto, el corazón quebrado, manchado por algo, arruinado, como un cuerpo que en la naturaleza entra en un proceso de descomposición y esparce mal olor" (2017: 8).
} 
“poder" que ostentan los gobiernos de los Estados donde, a veces, la corrupción se inicia en un sentido parecido al de disgregación para posteriormente producir una implosión que se traduce en querer confundir y difuminar los límites de los poderes legislativo, ejecutivo y judicial. Y todo ello, sin olvidar que los cadáveres se corrompen al disgregarse su materia corporal, la cual estaba unida por el principio de vida.

Si recurrimos a los diccionarios, resulta muy interesante y esclarecedor repasar las acepciones que de la palabra "corrupción" recoge Lomnitz (2000) a lo largo de la historia de dicho vocablo; así, un estudio diacrónico léxico nos remite: a la transformación del estado natural de una sustancia, a la sangre del condenado, a un carácter depravado o pervertido, al delito de cohecho o a la infidelidad, a un término con sentido jurídico y económico, a los idiomas contaminados o incorrectos por error o por alteraciones idiomáticas viciadas, a la adulteración y a la pérdida de inocencia por violación o seducción.

Por otra parte, Brioschi (2010) ha mostrado cómo la corrupción es un fenómeno que ha acompañado siempre a la historia del hombre, llegando a formar parte de nuestro acervo cultural, comprendiéndose como una tara propia del ser humano, algo que nos recuerda al concepto teológico del pecado original, el cual nos acompaña marcando nuestra naturaleza humana que desde la más tierna infancia se doblega a los hechizos del poder (quiero - no quiero), del tener (mío - no mío) y del placer (gusta - no gusta). Así, desde nuestra niñez, las relaciones que nos constituyen en cuanto seres sociales que somos $-\mathrm{y}$ que nos permiten desarrollarnos en cuanto seres humanos con una condición personal relacional y perfectiva- se presentan a nuestra consideración responsable y a nuestra administración ética; de tal modo que cuando nos dejamos llevar por los cortocircuitos que rompen dichas relaciones nos vamos alejando paulatinamente de nuestro propia maduración personal y, en cambio, nos vamos encaminando a la creación de una doble naturaleza que, además de encontrarse aislada relacionalmente, implica la disgregación de nuestra personalidad, la cual se irá sintiendo cada vez más atraída por los bienes externos de nuestro actuar como son el despotismo, el dinero o la fama, olvidando los bienes internos pertenecientes a nuestro actuar como seres humanos, los cuales logran hacernos buenos con el bien y los bienes propios que nos corresponden por nuestra naturaleza (MacIntyre, 1982; 2016).

Dicha perfección teleológica del ser humano se constituye en cuatro alteridades fundamentales que son: con el absolutamente Otro (Dios), los otros (nuestros prójimos y hermanos), lo otro (cosmos, naturaleza y cosas) y uno mismo (conociéndonos a nosotros mismos). Estas relaciones son las que realmente nos permiten entendernos a nosotros mismos, lograrnos como personas y en último término salvarnos. En este marco que estamos 
describiendo del crecimiento personal de los seres humanos, la noción de corrupción se caracteriza por tener la capacidad de descentrarnos, con una fuerza que es centrípeta en su origen codicioso, avaro, autoritario, egoísta y hedonista, pero en un segundo momento se trasforma en fuerza centrífuga, de tal modo que el ser humano termina por convertirse en una mónada pétrea sin comunicación y llena de brechas internas que provocan una personalidad fragmentada y rajada y, por eso mismo, avocada a las neurosis más severas, lo que implicará la descomposición y disgregación de las relaciones constitutivas.

Si el médico y humanista Laín Entralgo (1993) definió al hombre y a la mujer como seres písticos - llamados a creer y ser creídos-, elpídicos-instados a esperar y ser esperados- y agápicos - necesitados de amar y ser amados-, la corrupción trasforma a la persona humana, según el papa Francisco (2015; 2017), en todo lo contrario: satisfecha, autosuficiente, ventajista, nominalista-gnóstica, superficial, ambiciosa, frívola, mentirosa, impúdica, sinvergüenza, hipócrita, triunfalista, mundana espiritual, inmanentizada, nepotista, proselitista, auto-justificadora, mediocre, simoniaca, indiferente.

A estas alturas, los lectores podrán haberse dado cuenta de que hemos hablado de la corrupción en términos no exclusivamente económicos. Y posiblemente, esto último necesita una aclaración antes de terminar este apartado. Como hemos intentado mostrar, la corrupción es algo más profundo de lo que normalmente se entiende. Es cierto que hemos comenzado por invocar una vuelta al lenguaje corriente, pero eso no implica quedarse anclado en una utilización determinada de un concepto, por muy mayoritario que sea ese uso. Creemos que -por los ejemplos que hemos ido poniendo- queda meridianamente claro que en el lenguaje común todos utilizamos el término de "corrupción" aplicándolo a varios campos semánticos, pero indudablemente su significado está ligado al ámbito de las relaciones económicas. En cierta medida, pasa lo mismo que con el estudio de la axiología, ciencia que se ocupa de los valores, pero todos sabemos que aunque el concepto de valor es más amplio y rico que su mero uso para describir la dimensión crematística de una realidad, en el día a día, la referencia al valor en términos de riqueza y posesión suele ser su comprensión y empleo principal. En definitiva, para concluir esta sección, podemos recordar las palabras del autor sagrado, según las cuales: "el dinero todo lo allana" (Qo 10, 19). 
2. UNA VISIÓN DE LA CORRUPCIÓN A LA LUZ DE LA SAGRADA ESCRITURA Y LAS ENSEÑANZAS DE LA IGLESIA TOMANDO COMO DISCULPA ALGUNAS AFIRMACIONES DEL PAPA FRANCISCO

Cuando el cardenal Jorge María Bergoglio fue elegido Obispo de Roma inmediatamente las librerías se llenaron de sus escritos. Es de todos sabido que el papa Francisco nunca se había dedicado a la teología, pero en sus distintos servicios pastorales había ido desarrollando una doctrina pastoral de carácter inductivo muy propia de la conocida teología del pueblo. Además, era conocida su influencia en la elaboración del Documento Final de Aparecida, correspondiente a la Quinta Conferencia General del Episcopado Latinoamericano y del Caribe, ocupando la presidencia de la Comisión encargada para su redacción. Teniendo en cuanta los datos anteriores y los años de formación académica del actual pontífice, el profesor Borguesi (2018) ha realizado un cuidadoso estudio sobre la líneas matrices y conductoras que le llevarán a describir una biografía intelectual del papa Francisco ${ }^{2}$. Con todo, está claro que desde el comienzo de su pontificado, la virtud de la misericordia pasó a tener una prioridad, como así nos lo presenta Scannone (2017) al describir la ética social del papa Francisco como el evangelio de la misericordia en el espíritu del discernimiento. Pero paradójicamente, esa misericordia que se entiende en términos de cercanía, donde Jesús se hace el encontradizo con el hombre, lo mira y lo elige como indica en su lema papal - miserando atque eligendo-, contrasta con otras afirmaciones muy duras del actual pontífice como son las expresadas en Evangelii gaudium, donde dirigiéndose a la economía reinante de libre mercado fundada en la "confianza burda e ingenua en la bondad de quienes detentan el poder económico y en los medios sacralizados del sistema económico imperante" (Francisco 2013a: n. 54), la acusa de "matar"; describiéndola como una economía de exclusión y de iniquidad que forja y elabora una "cultura del descarte", donde los seres humanos excluidos no son sólo explotados sino que siendo considerados "sobrantes" son verdaderamente "desechos" (Francisco, 2013a: n. 53).

Pues bien, en esa misma línea de contraste podemos situar sus duras y radicales afirmaciones sobre la corrupción: "Podríamos decir que el pecado se perdona; la corrupción, sin embargo, no puede ser perdonada. Sencillamente porque en la base de toda actitud corrupta hay un cansancio de trascendencia: frente a Dios que no se cansa de perdonar, el corrupto se erige como suficiente en la expresión de su salud: se cansa de pedir

2 Creo que debemos destacar también la obra editada por Michelina Tenace (2018), titulada Del clavo a la clave. La teología fundamental del papa Francisco y que citamos en las referencias de este trabajo. 
perdón” (Bergoglio, 2013: 27); "nos hará bien volver a decirnos unos a otros: “ipecador sí, corrupto no!', y decirlo con miedo, no sea que aceptemos el estado de pecado como un pecado más" (Bergoglio, 2013: 15).

Tales palabras parecen hacer referencia al reverso negativo del conocido concepto de la opción o intención fundamental, pero precisamente ahora esa elección holística no iría dirigida hacia Dios sino hacia el mal.

\section{1. La corrupción como estructura de pecado}

Las expresiones del papa Francisco nos pueden remitir a una comprensión de la corrupción como una concreción paradigmática del pecado social y de las estructuras de pecado que desarrolló en su magisterio el papa Juan Pablo II y que con una variada terminología habían ya introducido en el imaginario católico contemporáneo los obispos latinoamericanos en Medellín y Puebla ${ }^{3}$. Ciertamente que el pecado personal siempre tiene una dimensión social, pero con el concepto de pecado social nos referimos aquí directamente a esos pecados que el Compendio de doctrina social de la Iglesia define como:

Todo pecado cometido contra la justicia en las relaciones entre persona y persona, entre la persona y la comunidad, y entre la comunidad y la persona. Es social todo pecado contra el bien común y contra sus exigencias, en toda la amplia esfera de los derechos y deberes de los ciudadanos. En fin, es social el pecado que se refiere a las relaciones entre las distintas comunidades humanas (Pontificio Consejo justicia y paz, 2009: n.118).

Pero en Sollicitudo rei sociales, Juan Pablo II (1987) aportó una novedad interesante al incorporar la categoría de estructuras de pecado, la cual el Papa introduce cuando realiza una descripción de las causas por las que la situación social a nivel internacional no ha mejorado sino más bien empeorado,

3 Lógicamente, no toca ahora detenernos en el vericueto de la historia de recepción de estas categorías en el magisterio de la Iglesia hasta la aparición de Sollicitudo rei sociales (Juan Pablo II, 1987), simplemente daremos unas someras pinceladas: en Medellín (CELAM, 1968) se habló de realidades que expresan una situación de pecado", "pecados cuya cristalización aparece evidente en las estructuras injustas; Puebla (CELAM 1979) se refirió a esta noción como "situación de pecado social" (n. 28), "sistema marcado por el pecado" (n. 92), "estructuras creadas por los hombres en las cuales el pecado de sus autores ha impreso su huella destructora" (n. 281) y "pecado social" (n. 482, 487, 1032); Juan Pablo II (1984: n. 17) afirma que "la Iglesia, cuando habla de situaciones de pecado o denuncia como pecados sociales determinadas situaciones o comportamientos colectivos de grupos sociales más o menos amplios, o hasta de enteras Naciones y bloques de Naciones, sabe y proclama que estos casos de pecado social son el fruto, la acumulación y la concentración de muchos pecados personales". 
lo que provoca que se presente como "necesario denunciar la existencia de unos mecanismos económicos, financieros y sociales, los cuales, aunque manejados por la voluntad de los hombres, funcionan de modo casi automático, haciendo más rígidas las situaciones de riqueza de unos y de pobreza de otros" (n. 16). De esta manera, en el número 36 de la encíclica al pecado social —entendido como el "fruto, la acumulación y la concentración de muchos pecados personales" turas de pecado:

Si la situación actual hay que atribuirla a dificultades de diversa índole, se debe hablar de 'estructuras de pecado', las cuales - como ya he dicho en la Exhortación Apostólica Reconciliatio et paenitentia- se fundan en el pecado personal y, por consiguiente, están unidas siempre a actos concretos de las personas, que las introducen, y hacen difícil su eliminación. Y así, estas mismas estructuras se refuerzan, se difunden y son fuente de otros pecados, condicionando la conducta de los hombres (Juan Pablo II, 1987: n. 36).

A renglón seguido, el papa indica dos actitudes contemporáneas que comporten dichas estructuras de pecado, a saber:

El afán de ganancia exclusiva, por una parte; y por otra, la sed de poder, con el propósito de imponer a los demás la propia voluntad. A cada una de estas actitudes podría añadirse, para caracterizarlas aún mejor, la expresión: 'a cualquier precio'. En otras palabras, nos hallamos ante la absolutización de actitudes humanas, con todas sus posibles consecuencias (Juan Pablo II, 1987: n. 37).

A la luz de estas enseñanzas se pueden interpretar las expresiones del papa Francisco en las que se afirma que:

¡La corrupción no puede ser perdonada! La corrupción es el pecado que, en lugar de ser reconocido como tal y de hacernos humildes, es elevado como sistema, se convierte en costumbre mental, una manera de vivir (...). La corrupción no es un acto, sino una condición, un estado personal y social en el que uno se acostumbra a vivir. El corrupto está tan encerrado y saciado en la satisfacción de su autosuficiencia que no se deja cuestionar por nada ni por nadie (Francisco, 2016: 91; 93-94).

Desde esta clave interpretativa, se enciende que el pecador sí puede ser perdonado cuando reconoce su pecado, se arrepiente, pide perdón y se convierte; pero la corrupción no se perdona, es imposible porque es un

4 Esta afirmación se encuentra en la nota 65 correspondiente al mismo número 36 de la encíclica y nos remite a la encíclica anterior Reconciliatio et paenitentia. 
mal estructural, no hay un sujeto al que perdonar, ya sea individual o colectivo. Nos encontramos ante un verdadero pecado estructural, el cual, ciertamente, es responsabilidad de las personas que lo han originado y que lo mantienen con su constante situación pecaminosa. Los corruptos son los que colaboran con su corrupción personal, particular y concreta al mantenimiento de ésta y ellos viven en el estado de corrupción como si fuera su propia casa-hogar. En definitiva, el corrupto ha creado una doble naturaleza que se encuentra armonizada con la situación generalizada de los intereses corruptos que imperan y regulan gran parte de la sociedad que él mismo ha ido forjando. Por eso, creemos que es legítimo decir que la corrupción expresa el significado del pecado estructural al que los que están inmersos en la corrupción llenan de contenido, a la vez que se encuentran atrapados en la misma madeja por ellos formada, ya que como pecado estructural que es, la corrupción les lleva a seguir pecando por mediación de la propia red estructural que se autogenera y que, al mismo tiempo, les atrapa. En el fondo, estamos ante otra manifestación real e histórica de la mitológica historia de la Hidra de Lerna de renacientes cabezas, la cual nos evoca la experiencia del avance silencioso del mal en los tejidos de la sociedad, la hidra siempre avanza y al mismo tiempo multiplica sus cabezas, a la vez que atrapa a los incautos que caen hechizados de su magia tentadora.

Entendida como estructura de pecado, la corrupción en sí misma no puede perdonarse porque es un sistema, como bien señala Xavier Pikaza es un "sistema injusto", consistente en una verdadera "estructura demoniaca” (2017: 7). Lo que nos recuerda los laberintos diabólicos concéntricos de la muerte que señalaba el teólogo Jürgen Moltmann (2010) en su conocida obra El Dios crucificado. Siguiendo esta clave hermenéutica, la dimensión diabólica de la corrupción es disgregación como la misma etimología de diabólico indica: dia (a través, entre) y bolos (tirar, arrojar, el que tira entre dos). Por tanto, este aspecto diabólico nos evoca los significados de dividir, separar o arrojar uno contra otro. Moltmann (2010) enumera los siguientes laberintos diabólicos: en el campo económico nos encontramos con la pobreza que es provocada por la corrupción de la explotación y el dominio de clases, la cual se manifiesta en el hambre, la enfermedad y la mortalidad temprana; dentro de la pobreza y en la dimensión política se encuentra el laberinto de la violencia, que se produce por la dictadura, el señorío de clase y los privilegios y se manifiesta en los derechos conculcados, las espirales violentas, la carrera y venta de armamentos so capa de prevención y disuasión. El siguiente laberinto es el del extrañamiento racial y cultural y que se incluye dentro de los anteriores de la pobreza y la violencia, en este círculo diabólico es donde los hombres se hacen manipulables, acomodados, dominables, privados de iniciativa y vendidos al más 
fuerte y rico, lo cual se manifiesta, según el teólogo alemán, en la opresión y alienación racial, cultural y tecnocrática. Los círculos diabólicos anteriores se unen en el círculo laberintico del abuso de la naturaleza en aras de la industria, todo ello provocado por la búsqueda de un progreso técnico e industrial que se manifiesta en una crisis ecológica amenazadora de los medios de subsistencia y de la vida en cuanto tal; para concluir con el último laberinto concéntrico que es "el laberinto diabólico del absurdo y el abandono de Dios" (Moltmann, 2010: 368-375).

Atrapado en las hidras que le aferran a estos laberintos intercomunicados y que forman estos cinco círculos diabólicos, el corrupto rompe las relaciones sanas y buenas que le constituyen y le hacen crecer como ser humano y, en la obnubilación a la que está sometido por tal situación, se le presenta como muy difícil la conversión, especialmente por la falta de conciencia de su situación personal y de su falta de sensibilidad por los pecados. El corrupto cuando llega a estos extremos ya no es sólo un pecador, sino un corrupto atrapado en la red o entramado de la corrupción, de tal modo que no es capaz de reconocer su propia situación y cree que ese mundo -como los encadenados de la caverna de Platón- es el único posible, sin percatarse de que él mismo es un corrupto colaborador acrítico del modo de vida que ha creado. Por eso, su situación -clínicamente hablando- es de extrema gravedad y la salida sólo puede discurrir por un proceso de "curación" (Bergoglio, 2013: 19). Una curación que implica procesos de liberación para que el corrupto convertido pueda ser perdonado; pero no nos engañemos con falsas esperanzas: la corrupción en sí misma debe ser aniquilada, sin pararse a mirarla a los ojos o dialogar con ella.

\subsection{La corrupción como pecado contra el Espíritu Santo}

Las palabras del papa Francisco también pueden evocarnos el conocido y misterioso texto en el que Jesús afirma la imposibilidad de perdón para los pecados contra el Espíritu Santo (Mt 12, 22-37; Mc 3, 28-30). La interpretación más directa es comprenderlas como dirigidas a aquellos que como los "maestros de la ley" atribuyen las obras de Jesús a Satanás y no al Espíritu. En la raíz de ello está la obstinación en cambiar la realidad; en este caso, nos encontramos ante unos signos milagrosos realizados por Jesús que sin embargo son atribuidos a un endemoniado, de tal modo que se tergiversan los hechos (Guijarro \& García, 2000; Brown, 2010). Pero, obviamente, de modo indirecto, este pasaje constituye para nosotros una advertencia: "no porque Dios no pueda perdonar todos los pecados, sino porque ese hombre, en su obcecación frente a Dios, rechaza y desprecia 
las gracias del Espíritu Santo" (Facultad de Teología. Universidad de Navarra, 2010: 1037).

De lo dicho se puede ver el paralelismo con las afirmaciones del papa Francisco y la corrupción. El corrupto está feliz de su situación, tiene una percepción distinta de la realidad y la tergiversa, se miente a sí mismo y miente a los demás, entra en el círculo laberíntico de la mentira que es también diabólico ya que el diablo es el "padre de la mentira" (Jn 8, 44): "En el núcleo mismo del juicio que hace un corrupto se instala una mentira, una mentira a la vida, una mentira metafísica al ser que, con el tiempo, se volverá contra quien la hace. En el plano moral esto es evitado por los corruptos, proyectando su maldad en otros" (Bergoglio, 2013: 37).

Como consecuencia, el corrupto "ha construido una autoestima que se basa en actitudes fraudulentas: pasa la vida en mitad de los atajos del oportunismo, a expensas de su propia dignidad y de lo de los demás (...). La corrupción hace perder el pudor que custodia la verdad, la bondad y la belleza" (Francisco, 2016).

Un texto paradigmático y que el propio papa Francisco señala es el pecado de Ananías y Safira (Hch 5, 1-11). El santo padre lo pone en relación al texto de la carta a los Hebreos que nos advierte que debemos vigilar "para que nadie sea privado de la gracia de Dios y para que no brote ninguna raíz venenosa capaz de perturbar y contaminar a la comunidad" $(\mathrm{Hb}$ $12,15)$ y lo comenta describiéndolo no como un simple pecado sino identificándolo como un "estado de corrupción" (Bergoglio, 2013: 50).

Para comprender el sentido profundo de este texto, me he servido de la investigación realizada por Vargas (2018), en este trabajo, el autor destaca que el pecado de estos ancianos atenta contra la unidad de la comunidad cristiana, reflejada en los bienes compartidos por "todos los creyentes" (Hch 4, 32), además de consistir en una mentira contra esa misma comunidad y el Espíritu Santo, verdadero y último fuente de unidad. Notemos que Ananías y Safira están llenos de Satanás $(5,3)$ y eso es lo que les lleva a mentir, además sin necesidad $(5,4)$, lo que provocará su castigo. La trama es recurrente en cuanto paradigma de corrupción: lo problemático es el afán de dinero y de riqueza, los bienes materiales y externos que llevan a abandonar la consideración de la excelencia de los bienes virtuosos, rompiendo la unidad de la comunidad a la que se pertenece y sirviéndose de la mentira y el engaño, es decir, manipulando la realidad y queriendo mantener los hechos en la oscuridad de lo secreto, aunque el texto nos descubre que todo es visible a los ojos de Dios. 
Lógicamente, dar respuesta a la cuestión ética de la corrupción en el terreno político, social, judicial y económico es una tarea que supera las capacidades de este estudio. En este apartado sólo intento realizar una descripción fenomenológica de la corrupción en un mundo globalizado, que, precisamente por eso, origina un modo y estilo de vida que se pretende universalizar y que se traduce en un modo uniforme de acercarse a las cuestiones sociales. En este contexto, incluso la protesta y la indignación que pretende salirse de la fila marcada por lo políticamente correcto es rápidamente incluida en unos parámetros y clichés concretos (Innerarity, 2015).

También la corrupción se mide y así tenemos los informes de varias ONG dedicadas a la medición de la corrupción como son los realizados periódicamente por Transparencia Internacional (2003) que define la corrupción de un modo tan sencillo como el abuso de poder otorgado para obtener un beneficio privado. Pero existen un numeroso grupo de organizaciones e instituciones que se dedican a ello como la Organización para la Cooperación y el Desarrollo Económico, creada en 1998, la Oficina de Lucha Contra el Fraude de la Unión Europea, la Oficina de Lucha contra el Soborno y los distintos organismos de control de los diferentes poderes como son los Tribunales de cuentas, las Oficinas anticorrupción, los Códigos deontológicos, los Informes de gastos y presupuestos, así como el trabajo de los medios de comunicación social. Creemos que como información y recogida de datos son instituciones e iniciativas necesarias para tomar conciencia del Lebiathan al que estamos incorporados, a la vez que su función debe estar al servicio de mantenernos informados sobre el mundo en el que nos encontramos y que estamos forjando individual y colectivamente.

Pero como bien señala Bernardo Pérez Andreo, estos datos no pueden ser más que una toma de conciencia que debe conducir a una reflexión sobre la realidad antropológica de la corrupción, así como a un análisis de los mecanismos que llevan a la perversión de nuestros sistemas e instituciones (Pérez, 2017: 19), lo cual nos conduce a la necesidad de un planteamiento ético que debe reclamar soluciones no sólo normativas sino educativas y virtuosas; donde la profundización religiosa y teológica nos llevará a añadir otras claves hermenéuticas como la posibilidad de conversión y la denuncia de la corrupción. Aunque eso vaya en contra de lo que muchas veces es políticamente correcto en la sociedad en la que nos movemos - la cual suele apelar en su defensa a una supuesta separación entre lo religioso y lo político por parte de absolutistas separacionistas de estas dos dimensiones, queriendo enmarcar y encorsetar toda la realidad en los marcos 
preestablecidos por la gran división de lo público y lo privado-. Sin embargo, no se puede negar que dicha denuncia es profética y que al igual que el profetismo del Antiguo Testamento (Jaramillo, 1992), personas como Martin Luther King o actualmente el papa Francisco son instancias religiosas desde donde han salido las denuncias más contundentes contra la desigualdad y la corrupción, aunque también habrá que reconocer que tales males se conocen por propia experiencia, al haberse también localizado en las instituciones religiosas a lo largo de la historia (Walzer, 2010: 226). Por otra parte, para no pecar de ingenuos, no podemos olvidar un fantasma que está detrás de toda la información recibida y que magistralmente expresó en el comienzo de su conocida obra Revel (2007: 23): “La primera de todas las fuerzas que dirigen el mundo es la mentira”.

Dicho todo lo anterior, hay que reconocer que cotidianamente nos encontramos con noticias relacionadas con la corrupción, debemos advertir que la siguiente numeración que ahora realizamos es sólo organizativa y no indica una prevalencia o importancia interna, aunque se puede encontrar cierta ley de concatenación.

\subsection{Echar mano a la caja}

En un primer lugar, podemos dirigir nuestra mirada a lo que solemos relacionar con la expresión "echar mano a la caja" (Sandel, 2007: 101) como son: "sobornos, pago de favores, tráfico de influencias, representantes de grupos de intereses que llenan los bolsillos de algunas autoridades públicas a cambio de contactos y favores" (Sandel, 2007: 101), el afán de lucro desmedido, tratados de libre comercio internacionales injustos por la situación de superioridad de una de las partes, mecanismos financieros y de libre comercio que conllevan una economía de "la exclusión", "del descarte" y en definitiva el sostenimiento a "una economía que mata", ya que el sistema es una dictadura que idolatra el dinero y crea un sistema social injusto de raíz (Francisco, 2013: 53; 54; 55, 59).

\subsection{Manos sucias}

En un segundo lugar, podemos seguir con la imagen anteriormente utilizada y hablar de las "manos sucias" (Walzer, 2010: 385-406), muy unida laberínticamente y concéntricamente con la anterior, con la imagen de estas manos queremos hacer referencia a la corrupción del poder —en España, corresponde a las instancias donde puedes solicitar la petición de "no me des dinero, ponme donde lo haya, que ya me ocuparé yo de tomarlo"- aquí se incluirían las siguientes situaciones corruptas: la informa- 
ción privilegiada, el nepotismos, el amiguismo, los partidismos ideológicos, el engaño al electorado -que puede ser legal democráticamente pero no legítimo moralmente- prometiendo a los votantes cosas imposibles (Walzer, 2010: 212), la extorsión, el chantajes, los privilegios burocráticos, las políticas populistas en vistas a adormecer a la sociedad civil, la creación de un temor popular, el control de la comunicación, los engrandecimientos profesionales, la demagogia, el abuso de la naturaleza y la destrucción del medio ambiente con meros fines de enriquecimiento particular, la educación condicionada a la ideología reinante, la no separación de poderes y el no reconocimiento de la autonomía de las cosas creadas (Gaudium et spes, 2000: n.36).

\subsection{Manos caídas}

En tercer lugar, lo que podemos llamar manos caídas: correspondiente a una corrupción que suele pasar más desapercibida, la que coincide con el pasotismo y la indiferencia de los estómagos agradecidos. Es la corrupción de la pasividad y la omisión ante el mal detectado, a veces con el analgésico de que nada se puede hacer o invocando un supuesto mal menor. El filósofo Michael Sandel lo describe de este modo:

Hay otra clase de corrupción que se está abriendo paso paulatinamente a la vista de todos. No conlleva robo ni fraude, sino más bien un cambio en las costumbres de los ciudadanos, un distanciamiento con respecto a las responsabilidades públicas (...) La corrupción cívica, acaba siendo más perniciosa que la primera (Sandel, 2007: 101).

Podemos evocar en este sentido el poema del pastor Martin Niemöller (1946):

Cuando los nazis vinieron a buscar a los comunistas, guarde silencio, porque yo no era comunista

Cuando encarcelaron a los socialdemócratas, guardé silencio, porque yo no era socialdemócrata.

Cuando vinieron a buscar a los sindicalistas, no protesté, porque yo no era sindicalista.

Cuando vinieron a por los judíos, no pronuncié palabra, porque yo no era judío.

Cuando finalmente vinieron a por mí, 
no había nadie más que pudiera protestar.

Todo esto nos debe llevar a la pregunta por las causas para que una sociedad entre en esta apatía, en especial los jóvenes que desconfían del mundo que les toca en heredad (CELAM, 2007: 77; 445). Así lo recogía también el Instrumentum laboris para el pasado sínodo de los Obispos dedicado a los jóvenes, la fe y el discernimiento vocacional, el que puso en evidencia:

...sus temores y algunas dinámicas sociales y políticas que, con diferente intensidad en varias partes del mundo, obstaculizan su camino hacia un desarrollo pleno y armonioso, causando vulnerabilidad y escasa autoestima. Algunos ejemplos son: las fuertes desigualdades sociales y económicas que generan un clima de gran violencia y empujan a algunos jóvenes en los brazos de la mala vida y del narcotráfico; un sistema político dominado por la corrupción, que socava la confianza en las instituciones y hace legítimo el fatalismo y la falta de compromiso; situaciones de guerra y de pobreza extrema que empujan a emigrar en busca de un futuro mejor. En algunas regiones, pesa la falta de reconocimiento de las libertades fundamentales, incluso en el campo religioso, y de las autonomías personales por parte del Estado; mientras que en otras regiones la exclusión social y la ansiedad por rendimiento empujan a una parte del mundo juvenil en el circuito de las adicciones (drogas y alcohol en particular) y del aislamiento social. En muchos lugares, la pobreza, el desempleo y la marginación llevan a un aumento del número de jóvenes que viven en condiciones de precariedad, tanto material como social y política (Sínodo de los Obispos, 2018: n.7).

\subsection{Manos mafiosas}

En cuarto lugar, podemos referirnos a una serie de corrupciones que pueden incluirse en la esfera de la expresión "manos mafiosas", lo que implica la interrelación de las anteriores "clases de manos" 5 . El desprecio por la vida ya sea en razón del sexo, la raza, la condición familiar, la condición de libertad, la ciudadanía, la ideología, la cultura, la educación, los posibles económicos, las discapacidades, la productividad o el tamaño del ser; por ahí se acercan el genocidio y el terrorismo, el aborto y la eutanasia. Pero también el tráfico de armas, de órganos, el narcotráfico, el aprovecharse de los jóvenes, la trata de personas, el desprecio, la conculcación de los derechos humanos y el ser humano como mercancía de sindicatos criminales y mafiosos.

5 Recordemos los duros discursos que el papa Francisco ha dirigido a la mafia siciliana, denunciando que no se puede creer en Dios y al mismo tiempo pertenecer a la mafia. 


\subsection{Manos técnicas}

En quinto lugar, la corrupción de las "manos técnicas", donde impera despóticamente la razón instrumental, del poder hacer, donde lo moral pasa a ser lo técnicamente posible y el ser humano es considerado un objeto técnico, llamado a ser dominado o incluso un derecho de los demás en el caso de los "bebés-medicamentos". En este nivel descrito, el ser humano pasa a ser criado, producido, seleccionado o mejorado.

\subsection{Manos vacías}

La corrupción de las "manos vacías", aunque éstas corresponden más a las víctimas que a los culpables. Los pobres - muchas veces- se ven atrapados en esta hidra de variadas corrupciones y participan de ella perdiendo la conciencia del mal y de la podredumbre donde se encuentran. La Iglesia ha denunciado y avisado de la corrupción que se implanta en el mundo de la pobreza, situación a la que muchos se ven abocados y en donde situaciones cambiantes provocan el olvido de las injusticias antes sufridas, pasando algunos a ser los nuevos corruptos, ya sea por grupos étnicos que llegan al poder después de otros (Sudáfrica después del apartheid o las relaciones entre las distintas tradiciones religiosas en Bosnia) o democracias en que la revancha al adversario político crece en una espiral ascendente o en injusticias organizadas contra los pobres, inmigrantes o minorías (Ignatieff, 2018). También la Iglesia ha advertido ante este grave problema que suele ser tratado de manera cínica por la sociedad. Así hablaba el Documento conclusivo de Puebla:

La riqueza absolutizada es obstáculo para la verdadera libertad. Los crueles contrastes de lujo y extrema pobreza, tan visibles a través del continente, agravados, además, por la corrupción que a menudo invade la vida pública y profesional, manifiestan hasta qué punto nuestros países se encuentran bajo el dominio del ídolo de la riqueza.

En los últimos años se advierte un deterioro creciente del cuadro políticosocial en nuestros países. En ellos se experimenta el peso de crisis institucionales y económicas y claros síntomas de corrupción y violencia. Dicha violencia es generada y fomentada, tanto por la injusticia, que se puede llamar institucionalizada en diversos sistemas sociales, políticos y económicos, como por las ideologías que la convierten en medio para la conquista del poder. Esto último provoca, a su vez, la proliferación de regímenes de fuerza, muchas veces inspirados en la ideología de la Seguridad Nacional (CELAM, 1979: 494). 
Y del Documento de Aparecida quisiéramos destacar un texto en el que se insta a

Formar en la ética cristiana que pone como desafío el logro del bien común, la creación de oportunidades para todos, la lucha contra la corrupción, la vigencia de los derechos laborales y sindicales; hay que colocar como prioridad la creación de oportunidades económicas para sectores de la población tradicionalmente marginados, como las mujeres y los jóvenes, desde el reconocimiento de su dignidad. Por ello, hay que trabajar por una cultura de la responsabilidad a todo nivel que involucre a personas, empresas, gobiernos y al mismo sistema internacional (CELAM, 2007: n.406).

\subsection{Manos blasfemas}

En séptimo lugar debemos también hablar de las "manos blasfemas" - tan dolorosas para la Iglesia en estos momentos por los casos de pederastia de sus miembros y el ocultamiento de los hechos- de los que llamando a Dios padre no tratan al prójimo como hermanos, especialmente de los miembros representativos de la Iglesia que se dejan llevar por la corrupción del dinero, del poder y del "hacer carrera". Es significativo el discurso del papa Francisco (2014b) a la Curia romana, donde podemos descubrir quince males que llevan a los miembros de la Iglesia hacia la que podemos identificar con el término de "mundanidad espiritual" (Bergoglio, 2013: 9) con la que el papa suele identificar la corrupción de los representantes de Iglesia, son los siguientes: el creerse por encima del bien y del mal, el laborismo como trabajo irreflexivo y voluntarista, la actitud hierática, el funcionalismo, el individualismo, el olvido de la salvación en la historia, la rivalidad, la mediocridad, la murmuración, la adulación a los superiores, la indiferencia, la cara "amarga", la codicia, el aislamiento individual o el que produce el cerrarse en el grupo de pertenencia, la mundanidad y el exhibicionismo de lo que se cree poseer. Pero como ya hemos introducido anteriormente, actualmente debemos hacer mención de los que han dañado la inocencia de los pequeños, aprovechándose de la confianza de los que creían acercarse a los representantes de Jesús, que pidió que los niños se acercasen a él, así como en la corrupción provocada por los miembros de la jerarquía para los cuales el prestigio de la institución eclesial fue más importante que el daño producido a las víctimas; aunque se hiciera con buena intención su juicio moral práctico fue claramente erróneo.

Lo trágico es que, al día de hoy, nos encontramos inmersos en una globalización de la corrupción y debemos reconocer que tenemos enfrente una hidra a la que le salen cada vez más cabezas de las que podemos 
acertar a cortar. Por otra parte, podemos recordar el diagnóstico que el psicólogo norteamericano Karl Menninger (1973) realizaba sobre nuestra sociedad caracterizada por el pecado de la irresponsabilidad colectiva y que con palabras de Pío XII (1946) se traduce en una pérdida de la conciencia de pecado y que - a la luz de lo expuesto- se ha convertido en una pérdida de conciencia del estado de corrupción en el que, en numerosas ocasiones, nos encontramos nosotros mismos como actores, ya que "se ha convertido en algo natural, hasta el punto de llegar a constituir un estado personal y social relacionado con la costumbre (...). Sin embargo, el Señor no se cansa de llamar a la puerta de los corruptos. La corrupción nada puede contra la esperanza" (Francisco, 2014a: 7).

\section{UNA PALABRA DE SALVACIÓN. EL DESTINO DE NUESTRA HISTORIA LO ESCRIBE DIOS}

Comenzábamos nuestras reflexiones recordando que el pecado rompe las relaciones constitutivas de la persona humana y afirmábamos sin vacilaciones que el pecado es una fuerza de división y disgregación, como nos recuerda el aforismo clásico de Orígenes: Ubi pecata sunt, ibi est multitudo (Homilia in Ezechielem, 9, citado por Catecismo Iglesia Católica, 1999: 817). También hemos dado un paso más y hemos relacionado la corrupción con las categorías de pecado social o estructural y las llamadas estructuras de pecado; de tal modo que nos han servido para diferenciar al pecador del corrupto y el pecado - por muy repetitivo que sea- de la corrupción en cuanto tal, como nos ha explicado el papa Francisco:

No hay que aceptar el estado de corrupción como si fuera un pecado más; aunque a menudo se identifica la corrupción con el pecado, en realidad se trata de dos realidades distintas, aunque relacionadas entre sí. El pecado, sobre todo si es reiterado, puede llevar a la corrupción, pero no cuantitativamente - en el sentido de que un determinado número de pecados hacen un corrupto- sino más bien cualitativamente: se generan costumbres que limitan la capacidad de amar y llevan a la autosuficiencia (2016: 92).

La siguiente pregunta que nos podemos hacer es sobre las consecuencias que este estado de corrupción tiene en las relaciones constitutivas del ser humano y creemos que una primera respuesta pasa por hacer notar que ya no nos encontraríamos ante una mera ruptura, sino ante la descomposición y desintegración de las mismas. Algo así como una opción o intención fundamental por mantenerse en la situación corrupta. Pasemos a realizar un intento de descripción de dicha corrupción en las cuatro consabidas relaciones esenciales, usando la terminología del profesor Olegario 
González de Cardedal (2004: 13) para referirnos a ellas: Nosce teipsum, Tu autem, Ubi frates tuus, Coram Deo.

Nosce teipsum: El hombre desea conocerse y conocer el sentido de su vida. Pero cuando entra en un estado de corrupción está encantado de haberse conocido, cree que ya lo sabe todo, se vuelve autosuficiente e inmanente; su ego se acrecienta, pero si nos preguntamos por cuáles son las razones y motivos por los que actúa descubriremos que sólo aspira a satisfacer sus necesidades desde su propia historia y ésta es comprendida como mera realización autónoma e individualista. El hombre de corazón corrupto cree conocerse, pero su ser está compartimentado, no tiene una unidad de vida, sino que su actuar es fragmentado en la disparidad de objetos de deseo que quiere conseguir sin considerar ninguna traba posible y sin importarle la cuestión de si eso que hace le lleva a comprenderse mejor en su verdad más honda y a crecer según lo que le corresponde como ser humano.

Tu autem: El ser humano ante la naturaleza y las cosas se presenta como un homo faber y dominador. Su relación con lo que le rodea es de abuso y dominio. En el terreno de la técnica todo lo que es posible pasa a ser moral y en terreno de la interacción con el medio ambiental se explota la naturaleza en provecho propio incluso siguiendo una postura cínica en la que se pone a Dios como disculpa, afirmando que es la voluntad de Dios, expresada en Gn 1, 28 - como denunció, aunque no del todo correctamente, Lynn White (1967) en su famosa conferencia y que ha servido como ariete de los reproches de los ecologistas a los cristianos-. Lo cierto es que la corrupción lleva a esconder y a disimular los impactos ambientales de algunas iniciativas empresariales a cambio de otros favores innombrables, esto, "suele llevar a acuerdos espurios que se evitan informar y debatir" (Francisco, 2015: 182).

Ubi frates tuus. Estas palabras latinas son la pregunta de Dios a Caín por su hermano Abel. El corrupto es un hombre codicioso y envidioso, se encuentra en estado de hombre encorvado sobre sí mismo, como indica la terminología desarrollada por san Agustín, Lutero y el teólogo Karl Barth sobre el pecado como causante del homo incurvatus in se. Como nos recuerda el papa Francisco, el corrupto vive en la apariencia y disimula con sus buenos modales y su enmascarada buena educación, participa de lo que el Papa denomina "cosmetología social" e incluso se vuelve proselitista, busca compinches, ya que en cierta medida son necesarios para tejer su trama, en la que "corrupción se consolida, convoca y sienta doctrina (...). No se trata de una convocatoria a cometer pecados, sino a enrolar en estado de pecado" (Bergoglio, 2013: 42-43), podemos decir en estado de 
corrupción, para así poder justificarse y al mismo tiempo considerarse limpio y puro mientras disimula mimetizado entre la masa. Pero no debemos olvidar que toda esa hipocresía oculta su verdadera naturaleza cainita.

Coram Deo: El corrupto se esconde de la verdad y, como tal, se aleja del Dios que le interpela. No necesita fines últimos, él es su fin en sí mismo. En la diferencia macquintariana entre los bienes internos a cada práctica (que marcan la excelencia de lo que se realiza como bueno y virtuoso) y los bienes externos (dinero, fama, prestigio, derechos sin deberes, poder sin autoridad) el hombre corrupto elige los segundos sin vacilar; así como tampoco se plantea la jerarquización de los bienes en general y el concepto de bien común queda virgen para su pensamiento (MacIntyre, 1982; 2016). En definitiva, para actuar, el corrupto no duda, lo importante son los bienes externos, acorde con su emotivismo y el relativismo en el que milita, aunque eso le implique un vacío existencia; en el fondo, tiene que sufrir una gran crisis para dar un paso hacia el planteamiento de esas cuestiones éticas, en un estado normal, él no se las plantea y las ve como ilusiones metafísicas y trascendentales. En este estado de cosas, para el corrupto lo único necesario es ser capaz de manejarse en la vorágine de esta vida, para lo que utiliza las normas que le permiten lograr los objetivos marcados por el Estado y el mercado. Ciertamente, Gilbert K. Chesterton tenía razón cuando escribió que "cuando se deja de creer en Dios, enseguida se cree en cualquier cosa" (citado por Navascués, 2017), pues bien, el corrupto cree en sí mismo, en el dinero, en su placer y en su poder.

Todo esto configura una situación reinante de la época globalizada en la que se mundializa la corrupción, constituyendo una forma de vivir y de pensar. No se puede negar que la corrupción ha existido siempre, como ha demostrado plásticamente Brioschi (2010), pero actualmente nos encontramos ante "un nivel de corrupción nunca antes visto, porque no es solo que se dé el soborno, la extorsión, el fraude, el robo o el clientelismo, tipologías habituales de la corrupción, sino que es un sistema corrupto en sí mismo" (Pérez, 2017: 146), donde una minoría despilfarra , contamina y disfruta a expensas de una mayoría que es tratada como mera mercancía y que es valorada por lo que produce no por su dignidad, lo que conlleva a que más de un tercio de humanidad no pueda cubrir sus necesidades y un $11 \%$ de la población pase hambre (FAO, 2017).

Creo que es esclarecedor el análisis que realiza MacIntyre (2016). Ciertamente, que debemos reconocer y elogiar los logros conseguidos en los últimos tiempos, por ejemplo, en el campo de las libertades y en los reconocimientos sociales, así como en las manifestaciones artísticas y culturales, pero lo que es innegable es que esto ha ido unido a nuevas desigualdades, nuevas pobrezas y a descarríos de los deseos. Ante esto, no nos po- 
demos engañar ni caer en una especia de neo-maniqueísmo, tanto los logros como los retrocesos pertenecen una misma estructura política y económica. En ese sentido, los Estados modernos se presentan como democráticos, pero a través de unas institucionalizadas acciones de elección colectiva en las que los posibles candidatos son preestablecidos por grupos ya formados como son los partidos políticos y donde la clase social y la educación recibida rompen la supuesta garantía igualitaria que se propugna en las sociedades modernas. Si el Estado se configura en un contrato implícito entre los que ostentan el poder estatal burocratizado y los que reciben ciertos beneficios, las relaciones del mercado también son reguladas por contratos de confianza en los que el capital tiene la preponderancia y donde la codicia no solo es una virtud sino un deber, si se invierte dinero, todos los implicados en esa inversión, los que ponen el capital, los que son empleados y los que producen deben ser codiciosos para que la inversión se rentabilice.

Esto configura en la modernidad una ética de Estado y una ética de mercado que se debe cumplir para que todo funcione y que sólo saliéndose del contexto del Estado o del mercado puede producir el interrogante por su fundamento o sentido. La situación predominante implica una ética que no se preocupa por los fines que hay que perseguir sino por los límites que hacen posible que el sistema siga funcionando; ahora lo importante es que los deseos de la modernidad sean uniformados por la misma modernidad. Como fruto, la modernidad ha dado lugar a una riqueza cultural procedente de su contexto capitalista, donde los goces, actividades y deseos son variopintos y heterogéneos. Hay una multiplicación de deseos y sin embargo es necesario elegir, pero ¿cómo? Ante esta pregunta la respuesta del hombre globalizado es algo como lo que sigue: Quiero de todo, a veces objetos incompatibles y que producen tensiones relacionales con terceras personas. La siguiente pregunta será sobre ¿cómo resolver esas incompatibilidades y tensiones? Para el que toma partido por la postura predominante en la sociedad actual, se caracterizará por mantener su autonomía individual, que como hemos visto en primer lugar conlleva -en confrontación con los demás- el establecimiento de un disenso en la jerarquización de los objetos a conseguir y desear y, en segundo lugar, implica la imposibilidad de un consenso sobre la existencia de un bien humano en cuanto tal, de tal manera que según sean las convicciones de cada uno, así se forjará su forma de vivir. En este estado de cosas, ser exitoso se traduce en ser capaz de competir con los demás y que las preferencias personales sean satisfechas antes que las de los demás. Pero para que la amenaza "hobbesiana", que implica el ser lobos entre nosotros, no llegue a concretarse en consecuencias desastrosas en las relaciones sociales, la ley se presenta como el marco que asegura las relaciones con los demás, tanto si 
eres de los privilegiados como de la masa de los perdedores (MacIntyre, 2016: 124-136).

Ante tan amplio panorama que, como se puede comprobar, esconde una forma de pensar filosófica y éticamente concreta y que sirve de humus intelectual a la extendida corrupción que vivimos, se necesita un verdadero cambio de paradigma ético. Un paradigma que nos obligue a reconsiderar las buenas razones que debemos tener para que obremos según lo que nos corresponde como seres humanos; hombres y mujeres que reconocemos nuestro bien común viviendo en sociedad, además de que —en medio de nuestros errores- seamos capaces de reconocer aquello que nos perfecciona como lo que somos: seres racionales y libres capaces de adherirnos a lo que nos hace buenos.

Si el pecado implica la ruptura de nuestras relaciones sustanciales y la corrupción la disgregación de las mismas, la teología y la fe cristiana nos descubren que estas instancias no tienen la última palabra porque más fuerte que ellos es la Unidad restablecida por la gracia de todos los hombres en Cristo, estando toda la creación aguardando impacientemente que nosotros nos convirtamos coherentemente en hijos de Dios por esa misma gracia, eso significará también la liberación de toda corrupción (Rom 8, 20-23).

En el terreno práctico social, esto implicará que por encima de las leyes del mercado, las relaciones mercantiles y empresariales y, por tanto, de los contratos y tratados de toda índole, se encuentre la búsqueda y la ejercitación de las prácticas personales y sociales que colaboran en la consecución del bien común. Por su parte, la Iglesia debe seguir promoviendo $\mathrm{y}$ anunciando racionalmente, lo que es lo mismo que mostrando su veracidad interna, los tan olvidados principios de la enseñanza social de la Iglesia. A su vez, en la vida social, económica y empresarial se debe promover el novedoso concepto de la "responsabilidad social corporativa", lo que permitirá, entre otros logros, que todas las instituciones en la sociedad actual abran los ojos a las crisis de toda índole - políticas, sociales, económicas, morales- que nacen de dentro de ellas mismas y, desde la humildad, sean capaces de dar un respuesta que además de aceptar los errores implique una regeneración; lo que en términos teológicos se puede traducir por el deseo convertido en la acción de una nueva creación, que buscando un desarrollo sostenible en todos los ámbitos tienda a ser un desarrollo integral que alcance "a todos los hombres y a todo el hombre" (Pablo VI, 1967: 14). 


\section{CONCLUSIÓN}

Después de este recorrido, debemos alabar todo intento normativo anticorrupción, pero la experiencia nos dice que no es suficiente, se necesita un rearme ético que comience desde la educación a la más temprana edad (CELAM, 2007: n.507) y una concienciación de la opinión pública para que la sociedad civil presione y se deje oír, ya que como indicamos más arriba, existe una corrupción muy deseada por los poderosos que se identifica con lograr una sociedad civil adormecida y, por tanto, pasiva. Es por eso que necesitamos una ética social donde la responsabilidad sea un verdadero principio que lleve a la acción, promoviendo la solidaridad entre todos seres humanos, también a nivel internacional, reconociendo la igualdad de todas las personas y desde donde se muestre la podredumbre de las estructuras de pecado y los mecanismos perversos que configuran la corrupción (Juan Pablo II, 1987: 39).

Frente a la disgregación y la descomposición de lo que se corrompe, no quisiera terminar estas páginas sin evocar los cuatro principios que, emanados de la doctrina social de la Iglesia, enuncia el papa Francisco en Evangelii gaudium (2013). Desde la tensión de bipolaridad que expresan ${ }^{6}$, nos deben situar en el polo opuesto a los círculos laberínticos y diabólicos de la corrupción: "El tiempo es superior al espacio"(n. 222-225), lo que conlleva trabajar a largo plazo; "la unidad prevalece sobre el conflicto" (n. 226-230), hay que aceptar sufrir en y por el conflicto, pacificar en las diferencias, pero también luchar por resolverlo y transformarlo; "la realidad es más importante que la idea" (n. 231-233), lo que nos lleva a no ocultar las cosas como son, a llamar las cosas por su nombre, sin intentar camuflar la realidad o torcerla a nuestro favor; "el todo es superior a la parte" (n. 234238), en la tensión entre la globalización y la localización, entre lo universal y lo particular hay que abrir la mirada sin evadirse de lo concreto, por muy putrefacto que sea, aquí se encuentra la gran labor de la evangelización, anunciando el Evangelio en su totalidad y a todos.

Como bien ha comentado el profesor José Román Flecha: "El Papa Francisco propone cuatro principios, que posiblemente resultarán un tanto difíciles para el lector medio. Sin embargo, piensa él que pueden ayudarnos a todos a orientar tanto la convivencia social como la fidelidad a un proyecto común que tienda a armonizar las diferencias sociales de un pueblo y de una comunidad" (Flecha, 2014: 87).

También la Iglesia en cuanto institución debe reconocer humildemente que es falible y que la corrupción no sólo existe afuera, hay trigo y

Para una profundización teológica de estos principios en el pensamiento de Francisco, véase Scannone (2017). 
cizaña y debe actuar, como institución pública que es -aquí me refiero de un modo especial a los casos de pederastia y su encubrimiento-, siguiendo las normativas vigentes en los Estados (Ammicht, Susin \& Sowle, 2014). No podemos obviar que nos va en ello el ser o no ser. Es claro que existe una teología del perdón ante los pecados, pero ante los delitos también existen los criterios legales, aquellos que en cuanto "penas" el derecho canónico también debiera utilizar, para —entre otras medidas- y desde la objetividad más escrupulosa juzgar la idoneidad necesaria, en el presente concreto, para ejercer —o seguir ejerciendo- el ministerio. En verdad, si analizamos las prácticas que se han utilizado en estos casos, hasta que han salido a la luz pública, se identifican con varias de las características con las que hemos descrito a la corrupción ${ }^{7}$. Y, sin embargo, también debemos decir, como a firmaba Jürgen Habermas, que sólo "las tradiciones religiosas proporcionan hasta hoy la articulación de la conciencia de lo que falta. Mantienen despierta una sensibilidad para lo fallido. Preservan del olvido esas dimensiones de nuestra convivencia social y personal en las que los progresos de la modernización cultural y social han causado destrucciones abismales" (2006: 14).

Para terminar, quisiera retomar aquello que enunciábamos de los laberintos diabólicos que denunciaba el teólogo Moltman, para finalizar con palabras suyas que, desde la fe en Cristo crucificado - y dando respuesta a los círculos diabólicos detectados- nos abren a la liberación de las cadenas propias de la corrupción:

Si hacemos pasar el lenguaje teológico de la presencia real de Dios a través de estas dimensiones de miseria, llegamos a la siguiente serie de identificaciones: en el infierno de la pobreza significa: 'Dios no ha muerto'. Es pan. En cuanto lo incondicionalmente-interesante, en cuanto el sentido actual, Dios está presente como pan. En el infierno de la violencia, la presencia de Dios se experimenta como liberación en orden a la dignidad y responsabilidad humana. En el infierno de la alineación, su presencia se advierte en la experiencia de identidad y reconocimientos humanos. En el infierno de la destrucción de la naturaleza, Dios está presente en la alegría por la existencia y en la paz entre hombre y naturaleza. En el círculo de la absurdidad y abandono por parte de Dios, Dios aparece, finalmente, en la figura del Crucificado, que proporciona coraje de vivir (Moltmann, 2010: 378).

\footnotetext{
7 A pesar de todo y aunque esto no vale como consuelo ni como disculpa por los graves hechos objetivos y concretos, conviene tener en cuenta que desde el punto de vista cuantitativo, no es la Iglesia el lugar donde más abusos se han cometido, hay espacios sociales con estadísticas mucho más elevadas.
} 


\section{REFERENCIAS}

-Ammicht, R., Susin, C. \& Sowle, L. (2014). Ubicuidad de la corrupción. Concilium, 358(5), 7-15.

-Bergoglio, J. (2013). Corrupción y pecado. (Segunda edición). Madrid: Publicaciones Claretianas.

-Brioschi, C. (2010). Breve historia de la corrupción. De la antigüedad a nuestros días. (J. Azaola, Trad.) Madrid: Taurus.

-Brown, R. (2010). Cristo en los evangelios del año litúrgico. Maliaño: Sal Terrae.

-Catecismo de la Iglesia Católica (1999). Madrid: BAC.

-CELAM (1968). Una iglesia en la actual transformación de América Latina a la luz del Concilio. Documento de Medellin, II Conferencia General del Episcopado latinoamericano. Bogotá: Celam.

-CELAM (1979). La evangelización en el presente y en el futuro de América Latina. Documento de Puebla. III Conferencia General del Episcopado latinoamericano. Bogotá: Celam.

-CELAM (2007). Discipulos y misioneros de Jesucristo para que nuestros pueblos en Él tengan vida. "Yo soy el Camino, la Verdad y la Vida". Documento de Aparecida. V Conferencia General del Episcopado Latinoamericano y del Caribe. Bogotá: Celam.

-Facultad de Teología. Universidad de Navarra. (2010). Sagrada Biblia. Comentario. Pamplona: EUNSA.

-FAO. Organización de las Naciones Unidas para la Alimentación y la Agricultura (2017). El Estado de la seguridad alimentaria y la nutrición en el mundo. Fomentando la resiliencia en aras de la pazy la seguridad alimentaria. Roma: FAO.

-Flecha, J. R. (2014). El gozo del anuncio. Comentario a la exhortación apostólica Evangelii gaudium del Papa Francisco. Salamanca: Kadmos.

-Francisco (2013). Exhortación apostólica Evangelii gaudium. Madrid: San Pablo.

-Francisco (2014a). Discurso a una Delegación de la Asociación internacional de Derecho penal (23 de octubre). Disponible en http://w2.vatican.va/content/francesco/es/speeches/2014/october/documents/papa-fran-

cesco_20141023_associazione-internazionale-diritto-penale.html

-Francisco (2014b). Presentación de las felicitaciones navideñas de la Curia Romana (22 de diciembre). Disponible en http://w2.vatican.va/content/francesco/es/speeches/2014/december/documents/papa-francesco_20141222_curia-romana.html

-Francisco (2015). Carta encíclica Laudato Si’. Madrid: San Pablo.

-Francisco (2016). El nombre de Dios es misericordia. (M. Cabré, Trad.) Madrid: Planeta.

-Francisco (2017). Prefacio. En P. Turkson, Corrosión. Combatir la corrupción en la Iglesia y en la sociedad, (pp. 7-12). Madrid: Palabra.

-Gaudium et spes (2000). En Concilio Vaticano II. Madrid: BAC.

-Gesché, A. (2004). El sentido. Dios para pensar VII. (X. Picaza, Trad.). Salamanca: Sígueme.

-González de Cardedal, O. (2004). Prólogo. En A. Gesché, El sentido. Dios para pensar VII (pp. 9-16). (X. Picaza, Trad.) Salamanca: Sígueme. 
-Guijarro, S. \& García, M. (2000). Comentario al Nuevo Testamento. (Sexta edición). Madrid: la Casa de la Biblia.

-Habermas, J. (2006). Entre naturalismo y religión. (P. Fabra y otros, Trad.) Barcelona: Paidós.

-Ignatieff, M. (2018). Las virtudes cotidianas. El orden moral en un mundo dividido. (F. Beltrán, Trad.) Barcelona: Taurus.

-Innerarity, D. (2015). La política en tiempos de indignación. Barcelona: Galaxia Gutenberg.

-Jaramillo, P. (1992). La injusticia y la opresión en el lenguaje figurado de los profetas. Estrella: Verbo Divino.

-Juan Pablo II (1984). Exhortación apostólica Reconciliatio et paenitentia. Madrid: San Pablo.

-Juan Pablo II (1987). Carta encíclica Sollicitudo rei socialis. Madrid: San Pablo.

-Laín Entralgo, P. (1993). Creer, esperar, amar. Barcelona: Galaxia Gutenberg.

-Lomnitz, C. (2000). Introducción. En C. Lomnitz (Coord.), Vicios públicos, virtudes privadas: La corrupción en México (pp.11-30). México D.F.: Centro de Investigaciones y Estudios Superiores en Antropología Social.

-MacIntyre, A. Ch. (1982). After Virtue. A Study in Moral Theory. (Second impression). London: Gerald Duckworth \& Co. Litd.

-MacIntyre, A. Ch. (2016). Ethics in the Conflicts of Modernity. An Essay on Desire, Practical Reasoning, and Narrative. Cambridge: Cambridge University Press.

-Menninger, K. (1973). Whatever became of sin? New York: Hawthorn books.

-Moltmann, J. (2010). El Dios crucificado. La cruz de Cristo como base y crítica de la teología cristiana. (Tercera edición; S. Talavero, Trad.) Salamanca: Sígueme.

-Navascués, J. (2017). Chesterton, el intelectual que ante lo absurdo del anglicanismo se hizo católico. Disponible en http://www.catolicidad.com/2017/04/chesterton-elintelectual-que-ante-lo.html

-Niemöller, M. (1946). Cuando vinieron por mí, ya no había nadie más. Disponible en http://www.milenio.com/opinion/irene-selser/danos-colaterales/cuandovinieron-por-mi-ya-no-habia-nadie-mas

-Pablo VI (1967). Carta encíclica Populorum progressio. Madrid: San Pablo.

-Pérez, B. (2017). La corrupción no se perdona. El pecado estructural en la Iglesia y en el mundo. Madrid: PPC.

-Pikaza, X. (2017). Prólogo. En B. Pérez, La corrupción no se perdona. El pecado estructural en la Iglesia y en el mundo (pp. 7-15). Madrid: PPC.

-Pío XII (1946). Radio mensaje a los participantes en el congreso catequético nacional de los Estados Unidos en Boston (26 de octubre). Disponible en http://w2.vatican.va/content/pius-xii/en/speeches/1946/documents/hf_pxii_spe_19461026_congresso-catechistico-naz.html

-Pontificio Consejo Justicia y Paz (2009). Compendio de doctrina social de la Iglesia. Madrid: BAC.

-Revel, J. F. (2007). El conocimiento inútil. (Sexta edición). (J. Bochaca, Trad.) Madrid: Espasa Calpe.

-Sandel. J. (2007). Filosofía pública. Ensayos sobre moral en política. (A. Santos, Trad.) Barcelona: Marbot. 
-Santos, C. (2018). Del aperturismo al sanchismo. Diccionario político español contemporáneo, desde los años finales de la dictadura y los primeros de la transición hasta hoy. Arch-letras, (1), 66-77.

-Scannone, J. C. (2017). Il V angelo della Misericordia nello spirito di discernimento. L éetica sociale di papa Francesco. Cittá del Vaticano: Libreria Editrice Vaticana.

-Sínodo de los Obispos (2018). Los jóvenes, la fe y el discernimiento vocacional, Instrumentum laboris. Disponible en http://www.synod2018.va/content/synod2018/es/documentos/instrumentum-laboris-para-el-sinodo-sobre-losjovenes-2018.html

-Tenace, M. (2018). Del clavo a la clave. La teología fundamental del papa Francisco. (Félix Menéndez, Trad.) Madrid: Biblioteca de Autores Cristianos.

-Transparencia Internacional (2003). Informe 2003. Disponible en http://webantigua.transparencia.org.es/barometro_global_2013/tabla_sintetica_barometro_2013.pdf

-Vargas, J. (2018). Pedro, ministro del juicio divino. El significado y la función de las palabras de Pedro en la muerte de Ananias y Safira (Hch 5, 1-11). Tesis para obtener el título de licenciado en Sagrada Escritura en el Pontificio Instituto Bíblico de Roma.

-Walzer, M. (2010). Pensar políticamente. (A. Santos, Trad.) Madrid: Paidós.

-White, L. (1967). The Historical Roots of Our Biologic Crisis. Science, 155(3767), 1203-1207.

Sumario: Introducción; 1. El uso común del término corrupción: etimología, significante y significado; 2 . Una visión de la corrupción a la luz de la Sagrada Escritura y las enseñanzas de la Iglesia tomando como disculpa algunas afirmaciones del Papa Francisco; 2.1. La corrupción como estructura de pecado; 2.2. La corrupción como pecado contra el Espíritu Santo; 3. Del hombre corrompido a la globalización de la corrupción; 3.1. Echar mano a la caja; 3.2. Manos sucias; 3.3. Manos caídas; 3.4. Manos mafiosas; 3.5. Manos técnicas; 3.6. Manos vacías; 3.7. Manos blasfemas. 4. Una palabra de salvación. El destino de nuestra historia lo escribe Dios. Conclusión; Referencias. 